\title{
CONSIDERAÇÕES SOBRE A TIPOLOGIA DO TURISMO BRASILEIRO
}

\author{
Alex Rodrigues Oliveira \\ Universidade do Estado do Rio de Janeiro (UERJ) \\ alexroliveira.geo@gmail.com
}

\begin{abstract}
Resumo
O presente artigo traz um esforço de abordagem temática cujo foco são as interações entre Geografia e Turismo. Ao pesquisarmos sobre Turismo e Geografia percebemos a gama de assuntos que podem ser relacionados por tais temáticas, fato percebido também por nossa bibliografia. O Turismo possui uma complexidade inerente e encontra na Geografia um bom suporte para analisar seus fenômenos. Neste texto objetivamos propor uma nova tipologia de funções turísticas, a luz dos estudos de Ribeiro (2003) e do Ministério do Turismo do Brasil (2010a). O presente artigo está dividido em três partes: a primeira discutindo os primórdios e introduzindo o tema do turismo; a segunda onde faremos uma discussão mais aprofundada sobre a utilização do Turismo pela ciência Geográfica; a terceira onde apresentaremos as tipologias pretéritas e proporemos uma nova categorização para as funções turísticas.
\end{abstract}

Palavras-chave: Geografia. Turismo. Tipologias.

\section{CONSIDERATIONS ON THE BRAZILIAN TYPOLOGY OF TOURISM}

\begin{abstract}
This article presents an effort to thematic approach whose focus on the interactions between Geography and Tourism. When search for Tourism and Geography we realize the range of issues that may be related to such themes, a fact also noted by our bibliography. Tourism has an inherent complexity in geography and is a good support to analyze its phenomena. In this paper we aim to propose a new typology of tourism functions, in the light of Ribeiro (2003) and the Ministry of Tourism of Brazil (2010a). This article is also divided into three parts: the first discussing the origins and introducing the theme of tourism; the second where we further discussion on the use of the Tourism Geographic science; the third where we will present the preterit typologies and propose a new categorization for tourist functions.
\end{abstract}

Key words: Geography. Tourism. Typologies. 


\section{Introdução}

O presente artigo traz um esforço de abordagem temática cujo foco são as interações entre Geografia e Turismo. Ao pesquisarmos sobre Turismo e Geografia percebemos a gama de assuntos que podem ser relacionados por tais temáticas, fato percebido também por nossa bibliografia. O Turismo possui uma complexidade inerente e encontra na Geografia um bom suporte para analisar seus fenômenos.

Neste texto objetivamos propor uma nova tipologia de funções turísticas, a luz dos estudos de Ribeiro (2003) e do Ministério do Turismo do Brasil (2010a). O presente artigo está dividido em três partes: a primeira discutindo os primórdios e introduzindo o tema do turismo; a segunda onde faremos uma discussão mais aprofundada sobre a utilização do Turismo pela ciência Geográfica; a terceira onde apresentaremos as tipologias pretéritas e proporemos uma nova categorização para as funções turísticas.

\section{O que é Turismo?}

A partir da década de 1960, no período da Guerra Fria, muitos estudiosos começaram a escrever teses, dissertações, entre outros, para mostrar cada vez mais a importância da Geografia no turismo, num campo transdisciplinar no conjunto das ciências sociais, além dos aspectos históricos, econômicos, psicológicos, sociólogos, antropológicos e jurídicos (RODRIGUES, 1997). Cruz (2001) irá afirmar que "o turismo é a única política social que consome elementarmente o espaço. Daí a importância de entendermos o interesse da geografia pelo turismo".

Ao realizarmos uma revisão sobre a concepção de turismo podemos perceber que o seu desenvolvimento é mais antigo do que a origem do próprio termo. As viagens produzidas para contemplação dos primeiros jogos Olímpicos (776 a.C); as construções de estradas pelo Império Romano nos séculos II a.C a II d.C que facilitaram as viagens; as peregrinações dos romeiros para Jerusalém; entre tantos outros acontecimentos anteriores, serviram de base para a associação do turismo ou do turista como indivíduo ou grupo que viaja (SEABRA, 2003). $\quad$ O turismo tem se apropriado das ideias desenvolvidas por outros ramos do conhecimento científico como a geografia, a economia, a antropologia, entre outras. Deste modo, nos apropriamos da perspectiva de Boullón (apud JUNIOR \& ITO, 2005) quando afirma que "o turismo não nasceu de uma teoria, mas de uma realidade que surgiu espontaneamente, e foi se configurando sob o impacto de descobertas em 
outros campos, como, entre outras coisas, o progresso da navegação e a invenção da ferrovia, do automóvel e do avião". Sendo assim, os conceitos geográficos apresentam-se como importantes formas de auxiliar na análise da configuração espacial que o turismo pode causar.

Entre as inúmeras definições de turismo, há que se destacar aquela adotada pela Organização Mundial de Turismo (OMT). Segundo a OMT, turismo compreende "as atividades que as pessoas realizam durante viagens e estadas em lugares diferentes do seu entorno habitual, por um período inferior a um ano, com finalidade de lazer, negócios ou outras"(2001). Todo tipo de viagem é considerado, hoje, turismo, independentemente da motivação do deslocamento. O que a OMT sugere com sua definição de turismo é que viagem e turismo são hoje sinônimos. Não se pode negligenciar o fato, entretanto, de que abarcar todo tipo de viagem como turística, conduz, entre outras coisas, à exacerbação das estatísticas e conceitos associados. O turismo não pode estar limitado apenas às questões econômicas, financeiras, políticas ou sociais. Deve ser considerado, também, as relações culturais e o reflexo temporal dessas influências em um determinado espaço. Rodrigues (1997) irá utilizar o termo espaço turístico para identificar a influência desta atividade no consumo do espaço uma vez que seus elementos são dotados de territorialidades e intencionalidades.

\section{Geografia do Turismo ou Geografia Turística?}

Diferentes fatores concorrem, com intensidades e ritmos, temporal e especialmente diferenciados, para a produção do espaço. Esses fatores não são apenas de ordem local, mas, também, em grande parte deflagrada em espaços globais. O turismo, tal como outras atividades introduz no espaço objetos definidos pela possibilidade de permitir o desenvolvimento da atividade. Além disso, objetos preexistentes em dado espaço podem ser igualmente absorvidos pelo e para o turismo, tendo seu significado alterado para atender a uma nova demanda de uso, a demanda de uso turístico (CRUZ, 2002). A produção do espaço turístico está cada vez mais se adequando a nova demanda de consumo atual, em que os espaços enquanto destinos turísticos estão sendo criados e recriados, com a finalidade de satisfazer as exigências de uma clientela dual.

A difusão da atividade turística, no entanto, ocorreu graças ao desenvolvimento tecnológico do século XIX (máquina a vapor, trem com vagão leito etc.) e século XX (desenvolvimento dos setores de transporte e comunicação). 
Entretanto, "se por um lado o turismo propiciou o desenvolvimento dos locais onde foi estabelecido; por outro, sua implementação resultou em fortes alterações no meio ambiente devido à exaustão do uso dos espaços selecionados e a preocupação tardia com o equilíbrio ambiental, além de embates criados entre os espaços de inclusão e de exclusão" (Adaptado de JUNIOR \& ITO, 2005). C Como afirma Cruz (2002, p.13) “a valorização dos espaços pelo turismo é dada em função de valores culturais e a cultura é própria de cada grupo social e mutável no tempo, territórios eleitos pelo turismo hoje não correspondem, necessariamente, aos territórios turísticos de amanhã". Daí a propriedade mutável e mutante do turismo, em eleger certas características e lugares para que se realize a turistificação. Tal turistificação hoje é incentivada pela iniciativa privada e setores turísticos de governos.

Podemos ainda citar o imaginário criado acerca de uma localidade turística, pois teremos na mídia o principal fator de alimentação do fluxo turístico, uma vez que esta gera e alimenta o processo fantasioso e implanta a imagem de um local perfeito para o desfrute do tempo livre. E o turismo procura ascender este lado fantasioso, trazendo para a realidade, com a ajuda da publicidade que resgata os sonhos e os transformam em ação. Ou seja, o imaginário vai impulsionar a valorização do espaço e retroalimentar a turistificação do local.

A necessidade de um planejamento que amenize impactos e desenvolva um turismo que traga mais benefícios do que malefícios é de extrema importância. O planejamento turístico é dependente do planejamento urbano, onde todos os levantamentos científicos, de uma dada localidade, resumem-se a levantamentos geográficos. A geografia consegue centralizar os impactos humanos no meio, em orientação territorial, ambiental e política, dando-nos a vertente de reorganização do espaço habitado, incluindo o espaço explorado pela atividade turística, fenômeno denominado como um deslocamento social no espaço.

A diversificação das formas do Turismo está associada ao território em que é praticado. A "matéria-prima” do turismo são os atrativos turísticos, os quais fazem parte e até confundem-se com as paisagens geográficas que, por sua vez, compõem o espaço geográfico. Neste sentido, a tentativa de criar tipologias baseadas nas funções turísticas, se monta num esforço em classificar as mais diversas atividades realizadas no espaço geográfico. Para tal, utilizaremos como base os estudos publicados pelo Ministério do Turismo Brasileiro (2010a) e de Ribeiro (2003). 


\section{Quais as Tipologias do Turismo?}

Setorizar ou simplesmente dividir as funções que uma cidade pode cumprir é uma tarefa árdua, que requer um bom tempo de pesquisa para sua realização. Apresentaremos aqui, as divisões propostas pelo Ministério do Turismo do Brasil (MTur) e por Ribeiro, e seus aportes teórico-metodológicos.

O MTur tem em suas publicações a tentativa de segmentar as atividades turísticas que ocorrem em território nacional, para tentar prestar assistências as cidades e indicar a realidade do setor de Turismo. Tais estudos estão dispersos em textos presentes no site

www.turismo.gov.br/turismo/o_ministerio/publicacoes/cadernos_publicacoes/14manuais.html $>$

Começamos pelo entendimento do MTur sobre a segmentação turística, que o órgão entende "como uma forma de organizar o turismo para fins de planejamento, gestão e mercado. Os segmentos turísticos podem ser estabelecidos a partir dos elementos de identidade da oferta e também das características e variáveis da demanda" (p. 3, 2010a).

A demanda turística ${ }^{1}$ será determinada pelas seguintes características: (a) Elasticidade - vulnerabilidade em relação a mudanças na estrutura dos preços e nas diversas condições econômicas; (b) Sensibilidade - vulnerabilidade em relação a condição sócio-políticas; e (c) Sazonalidade.

A sazonalidade se torna um fator preocupante, pois é um fenômeno que é caracterizado pela instabilidade entre a oferta e procura nos determinados períodos do ano, mais especificamente, no caso do turismo, conhecidos como épocas de alta estação e baixa estação (RODRIGUES, 1997).

Ao identificarem a demanda, a segmentação é realizada pela identificação de "certos grupos de consumidores caracterizados a partir das suas especificidades em relação a alguns fatores que determinam suas decisões, preferências e motivações, ou seja, a partir das características e das variáveis da demanda” (p. 4, 2010a). Ao aliarmos demanda, oferta e segmentação, teremos os tipos de turismos definidos pelo MTur.

Lembramos que qualquer tipo de classificação ou segmentação do turismo nunca dará conta da totalidade e da intencionalidade dos lugares turísticos, portanto, seria necessária uma investigação mais profunda para definir o que levou 
o governo a realizar estas classificações e quais os ganhos das cidades em assumir a funcionalidade proposta.

O MTur admite, por enquanto, a existência dos seguintes tipos de turismo: Ecoturismo; Turismo Cultural; Turismo de Estudos e Intercâmbio; Turismo de Esportes; Turismo de Pesca; Turismo Náutico; Turismo de Aventura; Turismo de Sol e Praia; Turismo de Negócios e Eventos; Turismo Rural; Turismo Gastronômico; Turismo Religioso; e Turismo de Saúde. Tais tipos de turismo serão detalhados adiante.

Ribeiro (2003) ao analisar o desenvolvimento das atividades turísticas no Estado do Rio de Janeiro estabelece uma tipologia para as cidades, baseada no Guia 4 Rodas $^{2}$, afim de recorrer a uma caracterização não oficial de tais localidades. Concordamos com Ribeiro quando este afirma que "em se tratando de uma tipologia na qual há predominância das diferentes modalidades turísticas, passíveis de mudança com o tempo, não corresponde a uma classificação estática, mas passível de mudanças" (2003, p. 85), por isso pretendemos, tal qual o geógrafo em tela, flexibilizar nossas tipologias.

Ribeiro utilizou-se de três elementos para realizar sua categorização: (i) a classificação da função turística, segundo o Guia 4 Rodas de 1999; (ii) as atrações; e (iii) os diferentes tipos de hospedagem, divididos entre pousadas, hotéis-fazenda e "hotéis comuns". A partir da análise de tais elementos elaborou-se a tipologia, distinguindo-se cinco grandes tipos, além das localidades de apoio, divididas em: Litorânea; Histórica/Rural; Rural/Ecológica/Aventura; Estância/Rural; Cultural/Rural; além de Apoio ao Turismo.

Reunindo as informações das duas pesquisas acima citadas, resolvemos unifica-las realizando a classificação das funções turísticas em relação às localizações geográficas e a finalidade das atividades realizadas, dividindo-as em: 1 - Urbana; 2 - Rural/Natural; 3 - Litorânea; 4 - Cultural; e 5 - Apoio ao Turismo. Cabe ressaltar que uma função pode aparecer em mais de uma classificação, devido a seu caráter polivalente. Neste contexto, produzimos o seguinte quadro:

Quadro 1 - Tipologias Das Funções Turísticas

\begin{tabular}{|c|c|}
\hline Categorias Turísticas & Tipos de Turismo \\
\hline 1 - Urbana & $1.1-$ Esportes \\
& $1.2-$ Estudos e Intercâmbio \\
\hline
\end{tabular}




\begin{tabular}{|c|c|}
\hline & $\begin{array}{c}1.3 \text { - Negócios e Eventos } \\
1.4-\text { Saúde }\end{array}$ \\
\hline 2 - Natural/Rural & $\begin{array}{c}2.1-\text { Aventura } \\
2.2-\text { Ecoturismo } \\
2.3 \text { - Esportes } \\
2.4 \text { - Estância } \\
2.5 \text { - Náutico } \\
2.6 \text { - Pesca } \\
2.7-\text { Rural/Agroturismo } \\
2.8 \text { - Saúde }\end{array}$ \\
\hline 3 - Litorânea & $\begin{array}{c}3.1 \text { - Esportes } \\
3.2 \text { - Náutico } \\
3.3 \text { - Pesca } \\
3.4 \text { - Saúde } \\
\text { 3.5 - Sol e Praia }\end{array}$ \\
\hline $4-$ Cultural & $\begin{array}{c}4.1-\text { Cívico } \\
4.2-\text { Étnico } \\
4.3-\text { Gastronômico } \\
4.4-\text { Místico e Esotérico } \\
4.5-\text { Religioso }\end{array}$ \\
\hline 5 - Apoio ao Turismo & - \\
\hline
\end{tabular}

Fontes: Brasil (2010a); Ribeiro (2003). Elaborado por: OLIVEIRA, A. R., 2014.

Esclarecemos que, em muitos casos, uma cidade irá receber mais de uma classificação por exercer mais de um tipo de turismo, como por exemplo, as grandes metrópoles como o Rio de Janeiro, que assume características Urbanas, Naturais/Rurais, Litorâneas e Culturais.

\section{Urbana}

Abarca todos os tipos de atividades turísticas que podem ser realizadas em perímetro urbano de uma cidade ou vila, definido por lei municipal (IBGE, 2011), e divide-se em quatro grupos: 
Alex Rodrigues Oliveira

1.1 - Esportes: compreende as atividades turísticas decorrentes da prática, envolvimento ou observação de modalidades esportivas.

1.2 - Estudos e Intercâmbio: movimento turístico gerado por programas de aprendizagem e intercâmbio, com a finalidade de proporcionar a um estudante experiência internacional.

1.3 - Negócios e Eventos: conjunto de atividades turísticas de caráter comercial, promocional, técnico, científico e social.

1.4 - Saúde: atividades turísticas decorrentes da utilização de meios e serviços para fins médicos, terapêuticos e estéticos, como hospitais, spas, balneários etc.

\section{Natural/Rural}

Compreende a todas as atividades realizadas fora do perímetro urbano, "inclusive nos aglomerados rurais de extensão urbana, povoados, núcleos e outros aglomerados” (IBGE, 2011, p. 7). Este tipo inclui oito subdivisões, a saber:

2.1 - Aventura: deslocamentos e estadas decorrentes da prática de aventura - "as experiências físicas e sensoriais recreativas que envolvem desafio, riscos avaliados, controláveis e assumidos que podem proporcionar sensações diversas" (BRASIL, 2010a).

2.2 - Ecoturismo: atividade turística que utiliza, de forma sustentável, o patrimônio natural - formações físicas, biológicas e geológicas.

2.3 - Esportes: compreende as atividades turísticas decorrentes da prática, envolvimento ou observação de modalidades esportivas, como voos livres, ciclismo off-road etc.

2.4 - Estância: modalidade que reúne elementos próprios ao descanso, como fontes termais e hotéis-fazenda.

2.5 - Náutico: caracteriza-se pela utilização de embarcações náuticas como finalidade da movimentação turística, neste caso também podendo receber a nomenclatura de Turismo Fluvial, Lacustre ou em Represas.

2.6 - Pesca: movimentação turística gerada pelas atividades de pesca amadora em lagos, rios e pesque-pague.

2.7 - Rural/Agroturismo: conjunto de atividades turísticas desenvolvidas no meio rural, simulando a vivência total ou parcial das atividades clássicas de uma fazenda produtiva. 
Alex Rodrigues Oliveira

2.8 - Saúde: atividades turísticas decorrentes da utilização de meios e serviços para fins médicos, terapêuticos e estéticos, como hospitais, spas, balneários etc.

\section{Litorânea}

Abrange localidades litorâneas, que compõem estratégias turísticas próprias, dividindo-se em cinco grupos:

3.1 - Esportes: compreende as atividades turísticas decorrentes da prática, envolvimento ou observação de modalidades esportivas, como futevôlei, surfe, bodyboard etc.

3.2 - Náutico: caracteriza-se pela utilização de embarcações náuticas como finalidade da movimentação turística, neste caso também podendo receber a nomenclatura de Turismo Marítimo.

3.3 - Pesca: movimentação turística gerada pelas atividades de pesca amadora em alto mar.

3.4 - Saúde: atividades turísticas decorrentes da utilização de meios e serviços para fins médicos, terapêuticos e estéticos, como hospitais, spas, balneários etc.

3.5 - Sol e Praia: movimentação turística gerada em função de recreação, entretenimento ou descanso em praias e resorts.

\section{Cultural}

Engloba o conjunto de localidades onde as atividades relacionam-se com a vivência de elementos significativos que valorizam e promovem os bens materiais e imateriais do local. Distinguem-se cinco tipos de turismo:

4.1 - Cívico: deslocamentos motivados pelo conhecimento de monumentos, fatos, observação ou participação em eventos cívicos, também chamado de Turismo Histórico.

4.2 - Étnico: atividades turísticas decorrentes da vivência de experiências em contatos diretos com os modos de vida e a identidade de outros grupos étnicos, como por exemplo, comunidades representativas dos processos imigratórios europeus/asiáticos, comunidades indígenas, entre outras.

4.3 - Gastronômico: movimentações turísticas suscitadas pela individualidade gastronômica de uma localidade. 
4.4 - Místico e Esotérico: atividades turísticas decorrentes da busca da espiritualidade e do autoconhecimento em práticas, crenças e rituais considerados alternativos, como o Templo da Boa Vontade em Brasília.

4.5 - Religioso: atividades turísticas geradas pela prática religiosa em espaços e eventos relacionados às religiões institucionalizadas, como Romarias, Festas de Santo etc.

\section{Apoio ao Turismo}

"Localidades que apesar de não apresentarem a função turística como atividade importante, exercem atividades de apoio em decorrência da presença de hospedagem e por estarem próximas de localidades turísticas." (RIBEIRO, 2003, p. 87). Cabe ressaltar que tais localidades estão sujeitas a processos de turistificação, modificando sua estrutura e atividades internas.

Além das diferenciações acima citadas, podemos encontrar, em pesquisas informais a agências de turismo, outras tipologias que incluem opções como Turismo de Compras, Turismo de Congresso, Turismo GLBT, Turismo da "Melhor Idade", Turismo PPNE (pessoas portadoras de necessidades especiais), Geoturismo, entre outras. Porém, tais tipologias ainda não são nosso foco de interesse, mas, podem ser incrementadas no futuro, sendo incorporadas por alguma categoria ou fundando a sua própria.

Nosso objetivo em sobrepor as duas tipologias definidas é realizar um contraponto da categorização oficial do Governo, com uma tipologia comum estudada por um geógrafo. Ao fundirmos estes dois estudos, estamos propondo um novo olhar sobre as duas obras pesquisadas - os textos do MTur e o Guia 4 Rodas. Não nos eximimos de quaisquer falhas no corrente trabalho, elas apenas expressam o quanto o tema ainda tem que ser discutido.

\section{Considerações Finais}

Diante do exposto, cabe efetuarmos algumas ponderações em relação a realidade turística. O Turismo em nosso país possui uma importante participação na economia, contudo, é uma grande dificuldade agregarmos valor a atrativos turísticos que envolvam a comunidade local. Portanto, não vislumbramos o Turismo enquanto atividade que solucionará os problemas econômicos e sociais de todo o país, pelo contrário, observamos muito durante as discussões do curso que as estratégias de mercado optam por excluir o local, favorecendo as 
grandes obras predativas de luxo. Assim, concordamos com Rodrigues (1997), quando esta afirma que "o Brasil necessita adotar políticas públicas que visam propiciar um maior planejamento para que o turismo se desenvolva no país de maneira a fornecer consciência da preservação ambiental, do patrimônio histórico e cultural do país” (p. 83).

O caminho ainda é longo na busca de solidificar o saber geográfico dentro do turismo, pelas proporções que essa prática social vem ganhando nos últimos anos. Nesse sentido, devemos dar enfoque a esta prática que movimenta milhões de pessoas em todo o mundo, e que, é consumidora do espaço geográfico, sendo vista como o principal objetivo dos seus consumidores na busca de aproveitamento do tempo livre.

Para concluir o debate que, cada vez mais se abre para abordar esse fenômeno global, pode-se dizer que o turismo serve para alimentar a reflexão na geografia (RODRIGUES, 2008). Mesmo assim, é necessário buscar o aprofundamento na reflexão geográfica para entender o fenômeno do turismo, contemplando sua natureza que é complexa e múltipla.

\section{Notas}

${ }^{1}$ A demanda turística utiliza como variáveis os fatores: demográficos (idade e sexo); sociológicos (religião, profissão, estado civil, formação educacional e nível cultural); econômicos (renda); e turísticos (transporte).

${ }^{2}$ Obra onde constam as principais localidades turísticas, comidas típicas, eventos, sugestão de compras, entre outros, com o objetivo de auxiliar os viajantes.

\section{Referências}

BRASIL, Ministério do Turismo. Marcos Conceituais. Brasília: Ministério do Turismo, 2010a. Disponível em: < http://www.turismo.gov.br/export/sites/default/turismo/o_ministerio/publicacoes/downloads_ publicacoes/Marcos_Conceituais.pdf>. Acesso em: 25 jul. 2014.

Ministério do Turismo. Segmentação do Turismo e o Mercado. Brasília: Ministério do Turismo, 2010b.

, Ministério do Turismo. Turismo Cultural: Orientações Básicas. Brasília:

Ministério do Turismo, 2010c.

CRUZ, R. C. A. Introdução à geografia do turismo. São Paulo: Roca, 2001. 
IBGE, Instituto Brasileiro de Geografia e Estatística. Conceitos e definições do censo demográfico de 2010. Rio de Janeiro: IBGE, 2011.

JÚNIOR, X. S.; ITO, C. A. Turismo e Espaço: uma leitura geográfica da interferência da atividade turística no processo de (re)organização sócio-espacial do município de João Pessoa-PB. Scripta Nova, Barcelona, v. IX, n. 194 (116), 1 de ago. de 2005.

OMT, Organização Mundial do Turismo. Introdução ao Turismo. Madrid: OMT, 2001. RIBEIRO, M. A. Turismo no Estado do Rio de Janeiro: ensaio de uma tipologia.

GEOgraphia, Rio de Janeiro, ano V, n. 10, p. 79-91, 2003.

RIBEIRO, M. A. Categorias Analíticas do Espaço e Turismo: o exemplo da Fortaleza de Santa Cruz, Niterói/RJ. GEOgraphia, Rio de Janeiro, ano VIII, n. 16, p. 83-98, 2006.

RODRIGUES, A. A. B. Turismo e Espaço - Rumo a um conhecimento transdisciplinar. São Paulo: HUCITEC, 1997.

Geografia do Turismo: novos desafios. In: TRIGO, L. G. G. (Org.). Turismo: Como aprender, como ensinar. São Paulo: SENAC, 2008.

SEABRA, L. Turismo sustentável: planejamento e gestão. In: CUNHA, S. Baptista da;

GUERRA, A. Teixeira (org.). A questão ambiental: diferentes abordagens. Rio de Janeiro: Bertrand Brasil, 2003. 